\title{
LA EXPERIENCIA ESCOLAR DE MAESTROS “INEXPERTOS”. BIOGRAFÍAS, TRAYECTORIAS Y PRÁCTICA PROFESIONAL
}

\author{
Andrea Alliaud \\ Universidad de Buenos Aires, Argentina
}

No tenemos oídos para escuchar aquello a lo cual no tenemos acceso desde la vivencia ${ }^{1}$

En este último tiempo he oído voces que aluden a ciertos cambios en las actitudes, percepciones y prácticas de los docentes, vinculando ese movimiento con una nueva o distinta realidad escolar. Nuevos sujetos ingresan a las instituciones educativas. Los mismos, es decir los que tradicionalmente ingresaban, ya no son los mismos. Nuevos escenarios sociales y culturales se "imponen" en las escuelas, a pesar de ser éstas instituciones fuertemente conservadoras. La cultura de masas. La proliferación de medios por donde fluyen y circulan los conocimientos y la información. Las comunicaciones. El respeto por las particularidades y la construcción de valores locales. Los acuerdos, la convivencia. Fenómenos de pobreza, fracaso y marginalidad. Las crisis, la fragmentación y la dualidad. Los avances científicos y tecnológicos. La exigencia de nuevas competencias y destrezas profesionales. La especialización. Distintos modelos de organización familiar. La acentuación de las diferencias intergeneracionales, los cambios en la niñez. Y podríamos continuar....

Acordamos que todos los ítems mencionados lograron sortear los muros y filtrarse en las instituciones escolares, configurando otras "realidades". Sin embargo, no estamos tan seguros de que los marcos de apreciación y valoración así como las prácticas de los docentes sean tan diferentes. Por el contrario, sostendremos que las mutaciones "detectadas" en el cuerpo magisterial, pueden ser interpretadas como acentuaciones de ciertos rasgos que caracterizaron desde sus orígenes al oficio de enseñar.

Vamos a reparar particularmente en los maestros. Las reflexiones esbozadas, tanto como el desarrollo que a continuación se presenta, surgen de una investigación recientemente finalizada que ha indagado en la historia escolar de doce "novatos". Al comenzar el mencionado estudio, y basándonos en diferentes trabajos realizados, sosteníamos que la biografía escolar, es decir el período vivido en la escuela por los maestros siendo éstos alumnos, constituye una fase formativa "clave" y que su abordaje resulta enriquecedor para entender la práctica profesional.

No es simplemente el recuerdo de un maestro o profesor especialmente valorado de la propia escolaridad. Es mucho más que eso, es todo lo que los docentes aprendieron en la misma institución (escolar) a la que regresan o de la que nunca se han ido, aunque posicionados ahora en el lugar del que le toca enseñar. Concretamente, nos estamos refiriendo a lo que los maestros han aprendido "en situación", en todos los años que fueron alumnos. Es aquello que se vive y experimenta en determinadas

\footnotetext{
${ }^{1}$ La frase corresponde a Friedrich Nietzsche, en Ecce Homo, obra autobiográfica, cuyo sub-título original fue "Como se llega a ser lo que se es". Algunas de estas cuestiones se tocan en este apartado y en general todo el artículo aborda esta inquietud desde una perspectiva social. Sin embargo, al igual que la obra citada de Nietszche, se trata menos de una mirada nostálgica o autocomplaciente del pasado y más de escribir y reflexionar para confrontar con él.

${ }^{2}$ Se trata de mi tesis de doctorado "La biografía escolar en el desempeño profesional de los docentes noveles". Presentada en la Facultad de Filosofía y Letras (UBA) en diciembre de 2003.
} 
circunstancias en las que se producen los aprendizajes de contenidos formalizados. Es lo aprendido "informal" o "implícitamente" en la prolongada estadía que uno pasa por las instituciones escolares. Dean Lortie (1975) lo denominaba "aprendizaje por observación" y alertó sobre su perdurabilidad e impacto en la práctica profesional de los "schoolteacher". Años más tarde Philip Jackson (2002) llamó "aprendizaje adicional" a eso otro que se adquiere de los maestros y profesores mientras éstos nos enseñan. Sin poder medir o probar sus efectos, el autor reconoce la existencia de las marcas o huellas (él mismo se siente marcado e influenciado) que los docentes dejan en los alumnos. Señala su operatividad en la enseñanza, al tiempo que alienta a apreciar esos trazos, a "comprender la realidad de su significación", a la hora de entender a las escuelas y los docentes.

Al reconocer la influencia que la escolaridad vivida representa para quienes se dedican a enseñar, algunos autores ampliaron el concepto de formación, remitiéndola a instancias que trascienden la preparación profesional y la prolongan en el tiempo. Desde estos planteos, la "biografía escolar", pasa a ser la primera fase de la formación docente:

"En realidad cabría hablar de varios procesos o fases de socialización profesional. La primera experiencia profesional que tienen los profesores, que es a todas luces decisiva, es la prolongada vivencia que como alumnos tienen antes de optar por ser profesor y durante la misma preparación profesional. (...). La fase de formación inicial es en realidad un segundo proceso de socialización profesional, donde se pueden afianzar o reestructurar las pautas de comportamiento adquiridas como alumno" (Gimeno Sacristán, 1992: 128).

Ferry (1990) concibe la formación como un "trayecto" que atraviesan los maestros y profesores, durante el que transitan por diferentes experiencias e interactúan con diversos cuerpos de conocimientos, enfoques y personas. Para el autor, todas estas experiencias son "formativas" y, por eso, la preparación profesional no puede explicarse a partir de una sola de ellas. Según los diferentes autores, en ese largo camino que los docentes recorren en todos los años que son alumnos, interiorizan modelos de enseñanza (Lortie, op. cit.); adquieren saberes y reglas de acción (Terhart, 1987), pautas de comportamiento (Gimeno Sacristán, op. cit.); construyen esquemas sobre la vida escolar (Contreras Domingo, 1987); se forman creencias firmes y perdurables (Jackson, op. cit.), imágenes ${ }^{3}$ sobre los docentes y su trabajo (Rockwell, 1985), teorías, creencias supuestos y valores sobre la naturaleza del quehacer educativo (Pérez Gómez, 1997).

Enfrentados con este caudal que proviene de la experiencia escolar que los maestros han protagonizado, llegamos a concebir la formación docente en su carácter genealógico y a entender la inserción profesional de los "nuevos" docentes como "re-inserción" de sujetos que se hallan "formados" (marcados o influenciados) por todo lo que vivieron y aprendieron en las instituciones escolares recorridas en el trayecto que los condujo de nuevo a la escuela. A pesar de oír los pesares de los maestros llamados "noveles", "novatos" o "principiantes" (referidos a dudas, temores e inseguridades que les provoca la tarea que les toca desempeñar) los hemos considerado "experimentados", atendiendo a la experiencia por ellos acumulada en su paso por la institución escolar. Aún catalogados como "inexpertos", los novatos cuentan con al menos quince años de "experiencia escolar", producto de su pasaje por los distintos niveles de

\footnotetext{
${ }^{3}$ Clandinin $(1986,1992)$ utiliza el término "imágenes" para conceptualizar la experiencia docente. Las imágenes son para la autora un componente del conocimiento práctico. En su trabajo, centra la atención en el análisis de dos imágenes: "el aula como un hogar" y "el lenguaje es la clave" (Cf Angulo Rasco, 1999).
} 
enseñanza, y aún del profesorado ${ }^{4}$. Es así que en nuestro estudio caracterizamos a los novatos, como maestros "formados" y "experimentados". El concepto de "experiencia formativa" nos fue de utilidad para elaborar tal caracterización, en tanto remite a todo aquello que se aprendió de la experiencia (escolar, en nuestro caso), mientras se vivió. Es lo aprendido en tanto "nos pasa" (como sujetos), por oposición a lo que simplemente pasa (Larrosa, 2000). Es la experiencia que forma parte de la "trama" de nuestras vidas y en tanto tal cobra significado (Huberman, 2000).

A medida que avanzábamos en nuestra investigación y sobre todo al trabajar con los relatos autobiográficos producidos por los doce maestros, fuimos radicalizando nuestros planteos hasta llegar a concluir que más que formados por sus propias experiencias escolares los docentes son "formateados". Posicionados como alumnos, quienes vuelven a la escuela o permanecen en la institución escolar, han sido socializados en ese mundo; han aprendido a moverse y a desenvolverse dentro de lo que distintos autores denominaron "cultura", "formato", "gramática" o "programa" escolar, que parece mantenerse (y por lo tanto reforzarse) durante la formación profesional para finalmente constituir el contexto laboral. Más allá de las peculiaridades institucionales y de las experiencias formativas allí protagonizadas por los distintos maestros, se trata de una estructura común y constante (estructurante) que, sostenemos, hay que considerar para comprender los esquemas de percepción y de apreciación que los sujetos portan en el presente y ponen en juego en su práctica profesional.

(Anderson y Blase, 1987) señalan la existencia de una "cultura escolar" que trasciende las particularidades de las distintas instituciones y se pone de manifiesto en la constancia estructural que mantienen las interacciones, la organización del espacio físico, los discursos y las formas de actuar. El rasgo más llamativo de los principios y prácticas educacionales es, para los autores, su uniformidad. La alta estabilidad del sistema escolar podría explicarse, para otros, por la creación de un "discurso o dispositivo pedagógico", gramática que ordena y posiciona a la vez que guía la transformación” ${ }^{5}$ (Cf. Caruso y Dussel, 1996).

En el mismo sentido, Vincet y Lahire (2001) sostienen que hay elementos permanentes que hacen a la realidad de la escuela y recurrencias que se evidencian en la particularidad de las distintas instituciones. Estos autores hablan de "formato escolar" y lo definen como aquello que "hace a la unidad de una configuración histórica, surgida en determinadas formaciones sociales, en cierta época y al mismo tiempo que otras transformaciones..." (Ibid: 35). El concepto, permite pensar como unidad lo que de otro modo sólo podría ser enunciado como características múltiples. Tyack y Cuban (op. cit.), por su parte, refieren a la "gramática escolar" como conjunto de tradiciones y regularidades institucionales sedimentadas a lo largo del tiempo, transmitidas de generación en generación por maestros y profesores; modos de hacer y de pensar compartidos, aprendidos a través de la experiencia.

\footnotetext{
${ }^{4}$ Desde esta perspectiva, los maestros novatos pueden considerarse "experimentados", en tanto poseedores de un caudal de experiencia escolar que fueron acumulando durante todos los años que fueron alumnos. Tyack y Cuban (2001) se refieren a los docentes como "experimentadores", en referencia a las habilidades y saberes con que enfrentan las reformas escolares, resaltando su carácter activo en estos procesos. La experimentación se realiza, para los autores, a partir de un saber que proviene de la experiencia. Esta apreciación nos llevó a adjudicar la categoría de "experimentados" a los noveles, considerando no sólo la experiencia del puesto de trabajo, sino también la que fueron adquiriendo como alumnos.

5 Para Foucault un dispositivo es "un conjunto decididamente heterogéneo que comprende discursos, instituciones, instalaciones arquitectónicas, decisiones reglamentarias, leyes, medidas administrativas, enunciados científicos, proposiciones morales, filosóficas, filantrópicas; en resumen: los elementos del dispositivo pertenece tanto a lo dicho como a lo no dicho. El dispositivo es la red que puede establecerse entre estos elementos" (Ibid: 1991, 128).
} 
A partir de lo anterior, es posible sostener que los maestros se formaron en un contexto (escolar) que, aunque producto de cierta época histórica, presenta constancias estructurales (uniformidades, recurrencias, tradiciones, regularidades) y formas de transmisión (experiencia directa, observación, comunicación) que le son propias. Los jóvenes maestros aparecen así formados, experimentados, formateados, en tanto tienen incorporadas las formas, de un espacio altamente regulado, formalizado, estructurado. Los maestros llamados "inexpertos" son portadores de modelos, concepciones y representaciones acerca de los procesos escolares, las escuelas, los docentes y su trabajo. Un saber propio y común entre quienes pasaron por las instituciones escolares y a ellas vuelven para trabajar. De este modo, el colectivo magisterial parece provisto de una "cultura", "formato"o "gramática" (escolar) constituida por significados, formas de pensar y de actuar compartidas; especie de esquema o estructura estructurante (habitus) que se "activa" en los puestos laborales, traducido en un sin fin de acciones particulares.

Siguiendo con estos planteos, podríamos añadir que los maestros han sido formados o formateados por un "programa institucional" (Cf Dubet, 2003) constituido en la modernidad que tiene una determinada forma y modos de socialización específicos. Cuatro rasgos fundamentales lo caracterizan: "la escuela siempre está ubicada bajo la empresa de un modelo cultural fuera del mundo, como una ciudad ideal"; "los profesionales de la educación deben ser definidos por su vocación más que por su oficio y en tanto ello su autoridad está basada en principios superiores"; "no acepta a extraños como tampoco a los que no se adaptan a sus reglas y mecanismos"; "se basa en la creencia que los procesos allí acontecidos liberan a los individuos" (Ibid: 2 - 5). Este programa, basado en principios laicos y republicanos, adoptó un formato religioso ${ }^{6}$ y ha permanecido a lo largo del tiempo:

"Durante largos períodos las escuelas se han mantenido básicamente similares en su operación central; tanto así, que estas regularidades han dejado su huella en los estudiantes, educadores y público como los rasgos esenciales de la "verdadera escuela" (Tyack y Cuban, op. cit: 20).

Es precisamente ese formato entendido como "Realidad escolar" o "verdadera escuela", el que invoca a ser revisado, re-estructurado, en función de las nuevas condiciones y desafíos del presente. Sin embargo, quienes "vuelven" a la escuela o nunca se han ido (los docentes) se encuentran, paradójicamente, con un espacio "conocido", "familiar", con la "escuela auténtica" y con una escuela extraña, diferente. Si bien se trata de una institución similar a la que vivieron y transitaron durante todos los años que fueron alumnos, la misma se presenta afectada, alterada, desestabilizada:

"A fin de cuentas, el viejo modelo de formación ha sido ampliamente desestabilizado y la relación pedagógica se transforma en un problema porque los marcos ya no son tan estables y porque un gran número de alumnos y estudiantes ya no son, a priori, creyentes" (Dubet, op. cit: 9).

Serán, por una parte, las condiciones "homólogas", esa familiaridad percibida o detectada, las que favorecerán que los esquemas o modelos conformados por los maestros a lo largo de la propia trayectoria escolar, actúen conformando sus prácticas y representaciones. Nutrida del pasado, la experiencia escolar "encarnada" en los sujetos nutre el presente y potencia sus efectos en tanto fue aprendida en situación,

\footnotetext{
${ }^{6}$ En "Los maestros y su historia: los orígenes del magisterio argentino", trabajo esta idea planteada por Dubet, en referencia al proceso de conformación de los sistemas educativos nacionales. Este modelo moderno, con un contenido laico y positivista, mantuvo el discurso religioso en las prácticas pedagógicas y discursivas de inculcación y legitimación de un nuevo orden cultural que se estaba conformando. La escuela aparece como templo del saber, los maestros como sacerdotes laicos en posesión de un mensaje salvador y redentor, destinado a "combatir la ignorancia". La pedagogía del ejemplo y del modelo a imitar, se institucionalizan como formas legítimas de educación, moralización, instrucción y formación de maestros y alumnos.
} 
mientras se vivió. Conforma el "sentido práctico", aquel que se les suele escapar a muchas propuestas "formales" de formación profesional. Se pone en juego en la práctica concreta, conjugándose con lo que explícitamente se enseñó y con las condiciones en las que la práctica profesional se desarrolla.

Serán, por otra parte, las extrañezas y diferencias las que produzcan ciertas disonancias, causen problemas, malestares o interferencias. Ocurre que aunque se trata de la misma institución, la escuela ya no es la misma. Aún resguardada y protegida la institución escolar se ve actualmente cambiada debido a la intervención de múltiples factores a los que hicimos referencia al comienzo. "La modernidad ha introducido un virus en las instituciones que las descompone poco a poco", al decir de Dubet. Esto quiere decir que el mismo programa "escolar" permanece aunque afectado, alterado.

¿Cómo enfrentan los nuevos y variados escenarios (realidades escolares) sujetos que han tenido otras experiencias? ¿Estarán preparados para escuchar o interpretar aquello a lo que no tuvieron acceso desde las propias vivencias? Los nuevos maestros formados, experimentados, formateados, vuelven a una institución que aún manteniendo las formas, alteró su propio funcionamiento.

\section{Los relatos siempre son narrados desde una perspectiva en especial}

En nuestra investigación concebimos la formación docente en su carácter genealógico, es decir, como un proceso de larga duración que comprende distintas fases y ámbitos de desarrollo. Por otra parte, la práctica profesional ha sido entendida como un ámbito de producción donde cuenta no sólo lo que formalmente se aprendió, sino y fundamentalmente, lo que se vivió y experimentó. Al caracterizar a los novatos como experimentados y formados, pretendimos darle especial entidad a las experiencias de formación protagonizadas por los maestros durante el largo período que fueron alumnos en el que transitaron por instituciones escolares/escolarizantes. Como dijimos, los profesorado o las instancias de preparación profesional son comprendidas dentro de este continuum y potenciarán los efectos escolares/escolarizantes siempre que conserven una lógica de formación isomórfica con el programa de los niveles para los que forman. Ya explicitados los conceptos centrales avanzaremos en sus relaciones.

En la investigación no se ha contemplado lo que los maestros hacen en el presente, ni tampoco lo que vivieron en el pasado, para desde allí buscar posibles conexiones o explicaciones causales. La inquietud se centró, más bien, en describir, analizar e interpretar aquello que los novatos recuperan (recrean) de su pasado vivido a lo largo de su trayectoria escolar, lo cual nos aportó elementos para comprender la práctica profesional. ¿Cómo evocan la experiencia que han protagonizado durante todos los años que fueron alumnos? ¿Cómo organizan sus propias producciones? ¿Qué cuentan? ¿Qué dicen? ¿Cómo lo dicen? La noción de trayectoria, en tanto camino recorrido que parte de la escuela y llega a ella, alcanza la dimensión subjetiva ya que alude no tanto a lo que ocurrió, sino más bien a la forma que utilizan los sujetos para describir ese recorrido escolar que han realizado. De todos modos, las producciones "subjetivas" fueron situadas y así analizadas e interpretadas teniendo en cuenta las condiciones "objetivas" en las que se produjeron y se producen ${ }^{7}$.

7 Para Bourdieu (1997) no se puede dar razón de un trayecto sin considerar las pos iciones sociales que en cierta medida condicionan o estructuran tanto los movimientos como los esquemas de percepción y valoración a ellas asociadas. En esta investigación hemos considerado las condiciones de vida y las características de las escuelas por las que transitaron los distintos maestros. Hemos trabajado con maestros que tenían una antigüedad en la profesión menor a los cinco años y que realizaron diferentes recorridos formativos. 
Brizman (1991) utiliza el término "cronologías de la formación", para referirse a las distintas etapas o fases tal como aparecen en los relatos de los maestros. La primera, es aquella que adquirieron a lo largo de sus experiencias acumuladas en las aulas; la segunda, corresponde a las experiencias vividas como estudiantes de la carrera docente; las prácticas constituyen la tercera, y la cuarta empieza cuando el estudiante de magisterio se convierte en maestro de aula (Cf Biddle y otros, 2000). En los relatos autobiográficos producidos por nuestros maestros aparecieron estas etapas "escolares", como los principales organizadores en torno a los cuales se produjeron significados particulares.

Nuestros maestros novatos se mostraron provistos de un caudal de saber "experiencial" que les permitió producir extensos relatos sobre buenos y malos maestros, buenos y malos alumnos, acerca de la escuela, de las instancias de aprendizaje valiosas, y de ellos mismos como profesionales. Sin embargo y dadas las limitaciones espaciales, en este artículo nos centraremos especialmente en trabajar aquello que han producido acerca de sí mismos; es decir, focalizaremos en el personaje que sobre ellos mismos han creado, luego de reconstruir el recorrido escolar realizado. De este modo, los maestros aparecerán ya no como "producto" de sus propias experiencias escolares sino como "productores" de las experiencias de otros, de las nuevas generaciones. Desde esta mirada sobre sí, lo evocado o recreado de la propia biografía escolar adquiere un nuevo significado.

La autobiografías como instrumentos y la perspectiva biográfico-narrativa como método y enfoque de abordaje, resultaron herramientas compatibles con nuestra preocupación acerca del carácter constructivo, creativo con el que nos interesaba abordar los recuerdos escolares de los maestros. Como ya lo anticipáramos, nos preocupamos por conocer cómo narraban o contaban las experiencias escolares aquellos que pasaron por la escuela y vuelven a ella (o nunca se fueron). Las autobiografías expresan algo más que hechos, acontecimientos o descripciones de la vida. Otorgan sentido. Constituyen formas de expresión y creación de sujetos, social e históricamente situados. Retomando a Bruner (2002), la inquietud de nuestro trabajo podría plantearse como sigue: ¿qué forma se le impone a la realidad cuando le damos los ropajes del relato? Son precisamente esas creaciones, esos modelos narrativos los que usamos para dar forma a nuestras experiencias cotidianas. Hablar de lo que uno vivió, de lo que a uno le pasó, implica una construcción y reconstrucción de nuestras experiencias y en ese proceder guiado por hechos, anécdotas y recuerdos, significamos lo vivido, aparecemos y nos proyectamos...

Distintas voces, distintos modos de percibir y significar, aparecieron en los relatos autobiográficos elaborados por los maestros novatos. Asimismo, se han detectado regularidades y recurrencias. Presencias comunes conviviendo con diferencias, explican la "vigencia" y permanencia de la cultura escolar encarnada o incorporada en sujetos que han protagonizado experiencias variadas y prolongadas en la misma institución (escolar) que constituye en el presente su lugar de trabajo. Al decir de Bruner, "la cultura no se da en una pieza, y tampoco su patrimonio de historias. Su vitalidad reside en su dialéctica, en su exigencia de llegar a un acuerdo con opiniones contrarias, con narraciones de índole conflictiva" (Ibid: 127).

Nuestros maestros por ellos mismos. La versión sobre sí

El personaje que nuestros maestros novatos construyen acerca de sí mismos resulta del entrecruzamiento de distintos dichos y miradas que se remontan a sus docentes y alcanzan a sus alumnos. La imagen que cada uno ha ido produciendo y que es reflejo de este juego especular, denota algunos rasgos comunes y ciertas diferencias. 
En todas las caracterizaciones, la relación interpersonal, el vínculo y el afecto con los alumnos aparecen como ingredientes que definen la tarea de enseñar. Son sus proporciones las que varían tanto como su "utilidad". Mientras que para algunos querer y mimar (como una mamá o papá) o llevarse bien (como una amiga/o) constituye el componente principal de la tarea que los convoca, para otros es sólo uno más. Asimismo, hay quienes apelan a una sonrisa, una caricia o al buen trato para... (motivar, dominar, incentivar o encantar), mientras que otros maestros quieren, se acercan, se contactan y tocan porque sí, o acaso para reparar o saldar alguna deuda personal: "trato de reparar cosas mías", "me llena el contacto con los chicos", "el trabajo me alimenta". Se not a en esta dimensión "afectiva - vincular" cierta "gradualidad" en el trato, tal como la referían los maestros: está el que se acerca, el que se contacta, y el que toca (mima y besa). También encontramos a los que pretenden que la relación o el vínculo establecido trascienda el tiempo y el espacio escolar y perdure por varios años.

Es interesante señalar que en algunas historias la vuelta a la escuela como maestro (quizás allí antes que en el momento de optar por la profesión), produce la reactivación de aspectos negativos o puntos oscuros de la propia historia escolar y familiar que se pretenden "reparar", "curar", evitando que a otros les pase uno padeció.

Absolutamente relacionado con el tema de la afectividad y en ciertos casos con las vivencias personales, aparece en algunos relatos la ayuda que el maestro brinda a los alumnos como otro ingrediente propio de la tarea de enseñar. Nuevamente en este caso puede aparecer como un aspecto central o como complementario, generalmente del afecto. En estas escenas el maestro se muestra ayudando a los alumnos en los problemas familiares, sociales o escolares que éstos presentan. Aquí también hay cierta gradualidad que va entre los que "escuchan" las dificultades y los que las "resuelven" o intentan hacerlo, llegando incluso a "posesionarse" por los problemas de los otros.

El personaje que va surgiendo a partir de los rasgos mencionados, se parece bastante a la maestra "buena" que nuestros maestros evocaron de la propia escolaridad que es dulce, cariñosa, atenta, que se involucra con los problemas de los alumnos (contiene y comprende), los trata bien, los quiere, los individualiza y hasta pasado el tiempo los reconoce o identifica. Estos atributos acompañaban, a su vez, a la sabiduría y la habilidad para enseñar, aualidades con las que era convocado y personificado el buen profesor. Sin embargo, varios de estos maestros evocan otra cualidad que valoraron de sus antiguas maestras y que muchos se la adjudican a sí mismos: la exigencia. Aún los más amigos, paternalistas o altruistas, no quieren ser "demasiado" buenos y representar al maestro/a carente de "dominio", "manejo" de grupo. Estos maestros quieren ser buenos pero no están dispuestos a perder el control de los que tienen a su cargo. En algunos casos y para lograr este cometido, suelen recurrir a los gritos, las sanciones disciplinarias o al exceso de actividad, aún asumiendo el riesgo de parecerse a la maestra "mala". En estos relatos el dominio o "manejo" del grupo de alumnos, suele aparecer como una condición necesaria para poder enseñar.

El maestro que principalmente quiere y ayuda a sus alumnos suele referirse a ellos como "sujetos a" (querer, ayudar, escuchar, incentivar, motivar o disciplinar) "para que" (se superen, respondan, tengan ganas de estar en la escuela, aprendan, o al menos permitan al maestro desplegar su actividad). Como

\footnotetext{
${ }^{8}$ Se ha interpretado el deseo de educar del pedagogo alemán Friedrich Froebel en la experiencia de su juventud desgraciada: "es cuestión de rehacer, a través del niño, el camino que no ha podido recorrer en el seno de una familia armoniosa. La obra educativa
} 
sostuvimos en otro trabajo (Alliaud, 2002) la motivación junto con el acercamiento, constituyen estrategias que suelen utilizar los principiantes para contener o lograr el dominio de grupo y hasta para contenerse a sí mismos: "trabajo desde el afecto los aprendizajes" (decía una maestra en relación a sí misma), "con su dulzura podía contenernos a todos" (nos contaba otra en referencia a una de sus maestras predilectas). Hay sin embargo dos maneras de concebir a los alumnos que muchas veces conviven en un mismo relato. Los alumnos pueden representarse como seres dormidos, pasivos, que es necesario revivir, activar o resucitar ("incentivar", "motivar", "impulsar", "empujar") y/o como individuos a los que hay que apaciguar, calmar ("aquietar", "contener", "disciplinar", "encantar, "dominar") para... los fines mencionados.

Privilegiar la dimensión afectiva o altruista de la profesión, constituyen versiones de un mismo discurso, "moralizador - normalizador", asociado con los orígenes de los sistemas educativos modernos y la profesión docente. Es precisamente esa gramática o formato originario el que configura las re-ediciones que realizan los jóvenes maestros en escenarios educativos "semejantes" y a la vez bien diferentes. No tenemos la intención en este trabajo de deslegitimar ese discurso y su presencia en las visiones y prácticas de nuestros maestros, transmitido en su propia trayectoria escolar a través de prácticas específicas para ser finalmente producido y reproducido de nuevo en la escuela. Es más, consideramos que muchas de las "promesas" igualadoras e integradoras asociadas a ese pasado (moderno) están todavía hoy inconclusas. Tampoco tenemos duda acerca de estas dimensiones (afectiva y altruista) como constitutivas la tarea de enseñar, así como de otras ocupaciones en las que se pone en juego el trato con las personas (más aún si son niños). De ningún modo pretenderíamos negar la existencia o aniquilar los rasgos predominantes de la "cultura escolar" en la que la cultura de los docentes como grupo social es prioritaria (Pérez Gómez, 1998). Ocurre que lo que suele aparecer como predominante puede abordarse de diferentes maneras y llegar a relativizarse o problematizarse y hasta re-significarse, siempre que se brinden condiciones formativas (en las instituciones de preparación profesional y en las mismas escuelas como lugares de trabajo) y oportunidades para hacerlo. De ser así, seguramente acarreará algunos beneficios en las prácticas de las escuelas, donde nuestros niños se forman y en las que nuestros maestros fueron y están siendo formados.

Hemos considerado relevante identificar cómo ciertos componentes originarios y constitutivos de la profesión de enseñar se re-editan por los "nuevos" maestros en el presente, en escenario educativos que consideramos "semejantes" y, a la vez, muy diferentes. Sin embargo, hemos contemplando también que el colectivo "magisterial" que ellos integran está conformado por sujetos que aún recorriendo una misma trayectoria o recorrido "escolar", lo han hecho por caminos diferentes. Hasta aquí vimos cómo nuestros maestros abordan estas cuestiones, prestando especial atención a las regularidades y recurrencias. Pero en nuestro trabajo también oímos otras voces.

Para algunos de nuestros maestros la tarea es algo más que ayuda y afectividad (o no es principalmente ayuda y afectividad) y los alumnos no son sólo son seres a acallar o a reanimar. El afecto y la ternura aparecen conjugados con otros componentes como el saber, la norma y la autoridad. Éstos últimos se presentan como competencias profesionales de los que enseñan, quizá, podríamos agregar, retroalimentándose mútuamente. Ello no significa la anulación o sumisión del otro (frente a uno que sabe todo y administra unilateralmente el poder que deviene de su posición) ya que, en las escenas escolares que estos maestros construyen, los alumnos suelen aparecen como protagonistas desde su alteridad. Se

será para él un modo permanente de cuidar, cuando no de curar, la herida original de su existencia" (Michel Soetard, en: Meirieu, 2001: 23). 
presentan como "sujetos que" (piensan, resuelven, inventan, construyen), antes que como "sujetos a". Aparecen en su diferencia o heterogeneidad, dentro de la masa escolar, que además de querer, ayudar hay que enseñar y respetar. Los alumnos se caracterizan como "otros" que co-protagonizan las escenas que estos maestros producen.

Detenernos en los dichos y miradas hacia los otros (sus alumnos y sus docentes) que produjeron nuestros maestros mientras creaban su propio personaje, nos proporcionó algunas piezas para armar los modelos que fuimos presentando. Hemos visto cómo nuestros maestros se referían a sí mismos y cómo ese decir se iba conjugando con las predicaciones de sus propios docentes. Respecto de los alumnos notamos que éstos pueden concebirse como sujetos que necesitan ante todo afecto o ayuda y que la tarea del maestro consiste principalmente en atender esas necesidades "insatisfechas", o que la educación escolar (y la tarea del docente) implica algo más como saber y estar en condiciones de enseñar. Antes de cerrar estas cuestiones, una última reflexión se impone. Si bien es cierto que la delegación hacia la escuela de determinadas funciones vitales y sociales desempeñadas en otro momento por el estado y las familias ${ }^{9}$ puede alimentar la dimensión afectiva y altruista de la profesión en los actuales maestros, también lo es que al sobre-dimensionar estos ingredientes se pierde la especificidad de la función educativa (la transmisión cultural) encomendada aún hoy a la institución escolar. La dimensión pedagógica suele quedar relegada en los modelos afectivos y altruistas más puros y asume una posición similar en aquellos otros donde el afecto, la ayuda, la contención, el disciplinamiento y hasta la motivación, se presentan como condicionantes necesarios que permitirían crear las condiciones para poder enseñar. Nos preguntamos, en este caso, si en el afán de estos maestros que se muestran preocupados y ocupados en motivar, querer y ayudar queda lugar para que en algún momento acontezca el enseñar.

\section{Justo aquí es preciso comenzar a cambiar lo que se ha aprendido}

Hallamos en los guiones producidos por nuestros docentes elementos de "lo escolar" (asociados con los orígenes de la escuela y la profesión de enseñar) que constituyen la estructura básica (el núcleo duro o matriz) a partir de la cual los actuales maestros otorgan significado a la tarea de enseñar. La vocación, el mandato salvacionista asumido ahora por cada maestro individualmente, la presencia de impulsos "desinteresados" (vivir por y para otros), el afecto, el cuidado, la atención, entre otros, parecieran revivir y re-editarse en condiciones sociales y culturales concretas por individuos que han tenido historias diversas aunque todos escolares. Hay un discurso que la escuela mantiene a través de los años y se encarga de transmitir, del que los maestros son sus portadores, cualquiera haya sido el recorrido biográfico realizado. Como ya dijimos varias veces en este trabajo, quienes son maestros no sólo están formados por la preparación profesional, sino que fueron formados o "formateados" y por qué no "escolarizados" por la experiencia vivida como alumnos. Lo que se aprende como alumno, afirmaba Lortie, se generaliza y convierte en tradición, constituyendo, así, una poderosa influencia que trasciende las generaciones.

Sin embargo, son esos significados culturales que "la" escuela transmite los que constituyen, a nuestro parecer, un anclaje "a-histórico", disponible en todos los tiempos y en distintas circunstancias los que se recuperan (diferencialmente), según los trayectos que transitaron los maestros y los puntos de llegada en que los ubican en el presente. ¿Qué queremos decir? Por una parte, los relatos biográficos

\footnotetext{
${ }^{9}$ En los orígenes de la profesión docente y de la escolaridad el maestro tenía encomendado cumplir las funciones básicas de socialización y moralización que se sostenía no podía desempeñar las familias, aunque el Estado aparecía como garante de ese cometido educativo.
} 
producidos por nuestros maestros revelaron una llamativa homogeneidad precisamente en su carácter de ahistoricidad. ¿Qué hubieran expresado quienes portan más años respecto de su propia escolaridad? ¿Qué podrán decir los futuros maestros que hoy son alumnos acerca de su experiencia escolar? No tenemos respuestas para estos interrogantes, pero sospechamos que los relatos no serían muy diferentes de los que produjeron nuestros noveles docentes. Seguramente, aparecerían buenos y malos maestros, ligados con el trato dispensado y la relación vincular; la escuela como escenario de multitudes en el que adquieren especial relevancia los actos que personalizan. La enseñanza y los aprendizajes de contenidos particulares relacionados con el nivel medio y podríamos continuar... A la hora de caracterizarse a sí mismos nuestros maestros re-editaron este discurso, asumiendo el rol del maestro bueno que ante todo quiere, ayuda y comprende a los alumnos.

Por otra parte, encontramos dentro de este guión general matices, y aún producciones que manifiestan otras apreciaciones las que, sin embargo, retoman algunos de los elementos mencionados. Notamos en este trabajo que no se trata visiones y valoraciones excluyentes, aunque sí diferenciadas, que se asocian tanto con los caminos transitados por los distintos maestros para llegar de nuevo a la escuela, como con las condiciones laborales variadas de las escuelas en las que ellos se insertan o re-insertan ${ }^{10}$ para trabajar. Lo que en nuestra investigación conformaron sub-grupos de maestros sean quizá voces aisladas de quienes terminarán, seguramente, alejados de las escuelas debido, entre otras razones, a las expectativas profesionales también diferenciales.

Ya cerca del final, insistimos en destacar la poderosa influencia que ejerce la trama que se ha ido entretejiendo durante la propia historia escolar en las prácticas, representaciones y percepciones de los actuales maestros. La búsqueda de los orígenes de las prácticas presentes nos conduce, así, al contexto en que la misma se fue gestando (la biografía escolar) y al origen de la profesión de enseñar que perdura con la transmisión de las generaciones sucesivas. Posicionados en el hoy, pretendimos comprender cómo ese pasado es re-editado por maestros concretos, teniendo en cuenta que los contextos sociales y los escenarios escolares son diferentes a los del momento en que el dispositivo o formato escolar se ha conformado. Entonces notamos que lo que resuena "familiar", "perdurable", "escolar", se conjuga con la presencia de cierto malestar, de cierta imposibilidad o impotencia que opaca la tarea específica. El malestar de los docentes. La crisis escolar. Y podríamos continuar...

Podemos adherir a argumentaciones sociales o económicas que expliquen estos desfases, mientras tanto los docentes se (auto) perciben incapaces para enseñar, desvalorizados, desamparados y desautorizados. Podemos añorar los viejos escenarios o renunciar. Pero podemos reparar también en el discurso y el "formato" o dispositivo escolar que se mantiene en el presente (en las instituciones y en los sujetos) y abordarlo desde la preparación profesional. En este sentido, puede ser posible apostar a un "modelo complejo de formación" que contemple la poderosa trama fundante de lo que se pretende cambiar. Concretamente, estamos interpelando a las prácticas pedagógicas que se desarrollan en los ámbitos de formación profesional, a fin de que introduzcan la dimensión de las trayectorias personales, constructoras de la experiencia ${ }^{11}$, y la dimensión del contexto escolar, con su historia y sus tradiciones, no como algo dado,

\footnotetext{
${ }^{10}$ Nos estamos refiriendo a maestros que han tenido otras experiencias formativas por fuera del circuito escolarizado que son además quienes se encuentran trabajando en instituciones escolares que ofrecen mayores posibilidades de formación y desarrollo profesional en servicio.

${ }^{11}$ Nos estamos referiendo a la importancia que representa recuperar el saber de experiencia. Ese saber sin pretensión de verdad que permite vehiculizar un sentido acerca de lo que nos pasa, al decir de Larrosa (op. cit). Ese saber que se adquiere en el modo
} 
objetivado ("Real"), modelado para la acción (modelación, fabricación de las futuras generaciones), sino como espacio "modelable", moldeable y explicable por la acción de sujetos (colectivos e individuales) en circunstancias históricas particulares. De este modo, consideramos relevante trabajar con las experiencias vividas por los maestros, que son a la vez portadores de ese legado o formato escolar y artífices del mismo. Situar, contextualizar, problematizar, revisar, confrontar, interpretar y explicar distintas experiencias escolares, puede ser un punto de partida inmediato para construir estrategias que brinden herramientas para actuar.

De ningún modo pretendemos evadir el conflicto (inevitable) que se presenta en el acto de educar. Simplemente pensamos en condiciones de formación que posibiliten que la "Realidad/realidades" escolar/es aparezca menos ajena y a la vez no tan familiar cuando se la concibe como un escenario para enseñar. Estamos convencidos que a partir de los textos que producen los maestros, leídos (y retrabajados) desde contextos sociales y situaciones particulares, la Pedagogía y los que estamos preocupados y ocupados en la tarea de formar tenemos algo que aportar, ¿enseñar?

\section{BIBLIOGRAFÍA}

ALLLIAUD, Andrea. Los maestros y su historia: los orígenes del magisterio argentino. Buenos Aires, Centro Editor de América Latina, 1993.

ALLIAUD, Andrea. "Los residentes vuelven a la escuela Aportes desde la biografía escolar"; en: DAVINI, M C. (coord.). De aprendices a maestros. Enseñar y aprender a enseñar. Buenos Aires, Papers Eds, 2002. (pp. 39-78)

ANDERSON, Gary y BLASE, Joseph. 1987. El contexto micropolítico del trabajo de los maestros. Universidad New México (mimeo).

ANGULO RASCO, Félix. "De la investigación sobre la enseñanza al conocimiento docente"; en: PÉREZ GómEZ, A.; BARQUín RUIZ, J. y ANGULO RASCO, F. (eds.) Desarrollo profesional del docente: política, investigación y práctica. Madrid, Akal, 1999.(pp. 261-319)

BIDDLE, Bruce; GOOD, Thomas y GOODSON, Ivor (eds.). La enseñanza y los profesores I: La profesión de enseñar. Barcelona, Paidós, 2000.

BOURDIEU, Pierre. Razones prácticas. Sobre la teoría de la acción. Barcelona, Anagrama, 1997.

BRUNER, Jerome. La fábrica de historias. Derecho, literatura, vida. México, Fondo de Cultura Económica, 2002.

CARUSO, Marcelo y DuSSEL, Inés. De Sarmiento a los Simpson. Buenos Aires, Kapelusz, 1996.

CONTRERAS DOMINGO, José. "De estudiante a profesor. Socialización y aprendizaje en las prácticas de enseñanza" ; en : Revista de Educación Nro 282. Madrid/MEC, 1987. (pp 203 - 231)

DUBET, Francois. “¿Mutaciones institucionales y/o neoliberalismo? Conferencia inaugural en el Seminario Internacional sobre Gobernabilidad de los Sistemas Educativos en América Latina. Buenos Aires, IIPE/ UNESCO. Noviembre de 2003 (mimeo).

como uno va respondiendo a lo que le va pasando a lo largo de la vida y que va conformando lo que uno es; ese saber que tiene que ver con lo que somos, con nuestra formación y nuestra trans -formación. 
FERRY, Gilles. El trayecto de la formación. Los enseñantes entre la teoría y la práctica. México, Paidós, 1990.

FOUCAULT, Michel. Saber y verdad. Madrid, La Piqueta, 1991.

GIMENO SACRISTÁN, José. "Profesionalización docente y cambio educativo"; en: ALLIAUD, A. Y DUSCHATZKY, L. Maestros. Formación, práctica y transformación escolar. Buenos Aires, Miño y Dávila Editores, 1992. (pp. $113-144)$

HUBERMAN, Michael "Perspectivas de la carrera del profesor"; en: BIDDLE, B.; GOOD, T. y GoOdSON, I. (eds.), op. cit.

JACKSON, Philip. Práctica de la enseñanza. Buenos Aires, Amorrortu Editores, 2002.

LARROSA, Jorge. Pedagogía profana. Estudios sobre lenguaje, subjetividad y formación. Buenos Aires, Novedades Educativas, 2000.

LORTIE, Dean. Schoolteacher. Chicago. The University of Chicago Press, 1975.

MEIRIEU, Philippe. La opción de educar. Barcelona, Octaedro, 2001.

PÉREZ GÓMEZ, Ángel. La reflexión y experimentación como ejes de la formación de profesores. Universidad de Málaga, 1997 (mimeo).

PÉREZ GómeZ, Ángel. La cultura escolar en el contexto neoliberal. Madrid, Morata, 1998.

ROCKWELL, Elsie (edit). Ser maestro. México, Ed. El Caballito, 1985.

TERHART, Ewald. "Formas de saber pedagógico y acción educativa o ¿qué es lo que forma en la formación del profesorado?"; en: Revista de Educación. Nro 284. Madrid. MEC, 1987. (pp. 133 -158)

TYACK, David y CUBAN, Larry. En busca de la utopía. Un siglo de reformas de las escuelas públicas. México, Fondo de Cultura Económica, 2001.

VINCENT, Guy; LAHIRE, Bernard y THIN, Daniel. "Sobre a história e a teoria da forma escolar; en: Revista Educacao. Año XVI, Nro 33. Belo Horizonte, Facultade de Educacao. Universidad General de Minas Gerais, 2001. (pp. $28-44)$ 


\title{
Contactar
}

Revista lberoamericana de Educación

\author{
Principal OEI
}

